\title{
Minimally invasive coronary artery bypass grafting with bilateral internal thoracic arteries: Will this be the future?
}

\author{
Pradeep Nambiar, MS, FRCS (Edinburgh), FRCSC-Canada (Cardiac Surgery), \\ Sanjay Kumar, MS, MCh (Cardiothoracic Surgery), FRCS (Edinburgh), FRCS (England), \\ Chander Mohan Mittal, MS, Mch (Cardiothoracic Surgery), FRCS, ${ }^{a}$ and \\ Kailash Saksena, MD (Anaesthesia) ${ }^{\mathrm{a}}$
}

\section{ABSTRACT}

Objective: The aim was to show that total arterial revascularization via a left minithoracotomy using bilateral internal thoracic arteries was not only feasible but also a safe and reproducible procedure with excellent midterm outcomes.

Methods: From August 2011 to August 2016, 819 patients underwent off-pump minimally invasive multivessel coronary artery bypass grafting using bilateral internal thoracic arteries harvested through a 2-inch left minithoracotomy incision, and complete revascularization of the myocardium was performed using the left internal thoracic artery-right internal thoracic artery Y composite conduit.

Results: A total of 819 patients underwent minimally invasive total arterial myocardial revascularization using bilateral internal thoracic arteries (left internal thoracic artery-right internal thoracic artery Y composite conduit) via a left minithoracotomy. The average number of grafts was 3.1. A total of 171 patients $(21 \%)$ had 4 grafts, and 557 patients $(68 \%)$ had 3 grafts. There were 6 mortalities $(0.7 \%)$, and 4 patients $(0.4 \%)$ had an elective conversion to sternotomy because of hemodynamic instability. The average hospital stay was 3.1 days. Coronary angiograms were performed in 195 patients $(23 \%)$, and computed tomography angiograms were performed in 172 patients $(21 \%)$ at 12 months; the grafts were patent. Four patients $(0.4 \%)$ required reintervention with angioplasty.

Conclusions: Multivessel total arterial revascularization was performed using the left internal thoracic artery-right internal thoracic artery Y composite conduit via a left minithoracotomy and showed that it was safe and reproducible. The midterm outcomes have been good, and coronary angiograms showed widely patent grafts. This novel technique may help optimize minimally invasive coronary surgery and the use of bilateral internal thoracic arteries. Further, this technique has the potential for decreased morbidity, shorter hospital stay, cosmesis, and earlier return to active life. (J Thorac Cardiovasc Surg 2018;155:190-7)

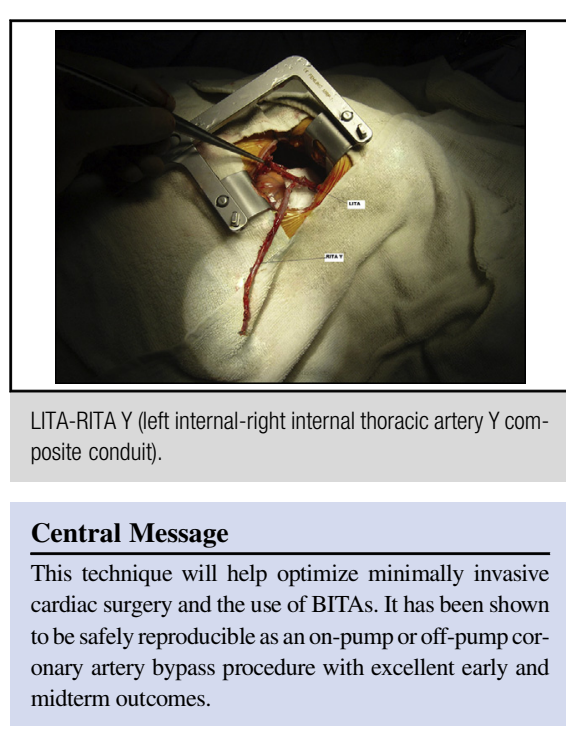

\section{Perspective}

This case series of 819 patients describes a technique to perform minimally invasive multivessel CABG through a left minithoracotomy using BITAs harvested under direct vision and as a LITA RITA Y composite conduit. This series has also shown that this technique was not only feasible but also a safe and reproducible procedure with excellent early and midterm outcomes.

See Editorial Commentary page 198.
Minimally invasive coronary artery bypass grafting (CABG) through a left minithoracotomy on its own or associated with hybrid coronary revascularization is being increasingly adopted and seems to be a promising and safe procedure. ${ }^{1-3}$ Harvesting of bilateral internal thoracic arteries (BITAs) under direct vision through a left minithoracotomy incision and use of the harvested BITAs

From the ${ }^{\text {a Department }}$ of Cardiothoracic Surgery Moolchand Medcity, New Delhi; and ${ }^{\mathrm{b}}$ Department of Cardiothoracic Surgery, Institute of Medical Sciences, Banares Hindu University, Varanasi, India.

Read at the 97th Annual Meeting of The American Association for Thoracic Surgery, Boston, Massachusetts, April 29-May 3, 2017.

Received for publication April 30, 2017; revisions received June 21, 2017; accepted for publication July 18, 2017; available ahead of print Oct 25, 2017. as a left internal thoracic artery right internal thoracic artery Y (LITA RITA Y) composite conduit for total arterial revascularization has been shown to be feasible with excellent early outcomes. ${ }^{4}$ The aim was to show that total arterial revascularization via a left minithoracotomy using BITAs was not only feasible but also a safe and reproducible procedure with excellent midterm outcomes.

\footnotetext{
Address for reprints: Pradeep Nambiar, MS, FRCS (Edinburgh), FRCSC-Canada (Cardiac Surgery), Department of Cardiothoracic Surgery, Moolchand Medcity, New Delhi 110024, India (E-mail: namb1@ hotmail.com). $0022-5223 / \$ 36.00$

Copyright (C) 2017 by The American Association for Thoracic Surgery https://doi.org/10.1016/j.jtcvs.2017.07.088
} 


\section{Abbreviations and Acronyms \\ BITA = bilateral internal thoracic artery \\ $\mathrm{CABG}=$ coronary artery bypass grafting \\ ITA $\quad=$ internal thoracic artery \\ IV $=$ intravenous \\ LAD $\quad=$ left anterior descending \\ LITA $\quad=$ left internal thoracic artery \\ LITA RITA Y $=$ left internal thoracic artery right internal thoracic artery $\mathrm{Y}$ \\ $\mathrm{LV} \quad=$ left ventricle \\ RITA $=$ right internal thoracic artery \\ TTFM $=$ Transit Time Flow Metry}

Scanning this QR code will take you to a supplemental video. To view the AATS 2016 Webcast, see the URL next to the webcast thumbnail.

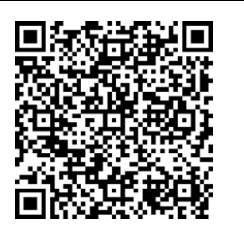

\section{MATERIALS AND METHODS}

From August 2011 to August 2016, a total of 819 patients underwent minimally invasive total arterial CABG through a 2.5- to 3-inch left minithoracotomy incision. The BITAs were harvested under direct vision, and total arterial revascularization using the LITA RITA Y composite conduit was done. Patients with left main stem disease and low ejection fraction less than $25 \%$ had an intra-aortic balloon pump inserted before induction of anesthesia. Patients with low ejection fraction and a dilated left ventricle (LV) were grafted on an empty beating heart using the peripheral femorofemoral cardiopulmonary bypass methodology. Intraoperative assessment of grafts was done using Transit Time Flow Metry (TTFM), and postoperative graft patency was checked using coronary angiograms, computed tomography coronary angiograms, or stress test. Pectus excavatum, severe chronic obstructive pulmonary disease with room air partial pressure of oxygen less than 60 , and intermittent atrial fibrillation and moderate mitral regurgitation requiring a Maze procedure and mitral repair were exclusion criteria for the procedure. All patients had both internal thoracic arteries studied during coronary angiogram preoperatively. Preoperative characteristics are detailed in Table 1.

\section{Surgical Technique and Postoperative Management}

The patients were placed in a supine position, with slight elevation of the left side of the chest to approximately 30 degrees (Video 1). The nondominant arm with normal modified Allen test was abducted to 90 degrees and placed on an arm support (in case the radial artery was required).

- Patients were intubated with a double-lumen endotracheal tube for single-lung ventilation, and standard invasive monitoring with arterial line, pulmonary artery catheter, and transesophageal echocardiography was performed. In patients with significant left main stem disease or poor LV function (ejection fraction $<25 \%$ ) an intra-aortic balloon pump was inserted before induction of anesthesia.

- A vascular Doppler and skin-marking pencil were used in surface marking of the RITA and the LITA.

- A 2.5- to 3-inch left infrathoracic incision was made 2 fingerbreadths lateral to the LITA surface marking, and the thoracic cavity was entered through the fifth intercostal space. The intercostal muscles were incised far beyond the limits of the skin incision to give an excellent exposure and less traction on the ribs, thereby reducing postoperative pain. Further, the serratus anterior muscle was never cut because this is one of the major causes of pain and discomfort after thoracotomy. The left fifth intercostal space was always chosen for entry into the thorax because the intercostal space height is greatest anteriorly in this space, thereby optimizing exposure.

- Approach to the thoracic cavity was always done through the left fifth intercostal space, resulting in the apex of the heart being manipulated and thereby minimal hemodynamic compromise rather than through the fourth space where the waist of the heart is manipulated, resulting in left and right ventricular outflow tract obstruction. Further, a transesophageal probe showed the movements of the ventricular wall's real time and any new mitral regurgitation. With the use of a minimal access intercostal retractor (Fehling Surgical Instruments Inc, Karlstein, Germany) in the fifth intercostal space, the ribs were gently spread. The pericardium was then opened in an inverted $\mathrm{T}$ fashion and the coronary arteries were inspected, after which the pericardiotomy was closed with interrupted 2-0 silk sutures (Figure 1).

- A Thorac-Pro internal thoracic artery (ITA) (Fehling Surgical Instruments Inc) retractor was then used in tandem with the minimal access intercostal retractor, and the chest was elevated (Figures 2 and 3). The left hemithorax was thoroughly inspected, and flow in the LITA was studied with a vascular Doppler. The fatty attachments between the pericardium and the sternum were completely divided, and on dissecting the pleural from the endothoracic fascia of the right chest wall, the RITA was well visualized (Figure 4).

- For enhanced visualization of the lower thirds of and beyond the bifurcation, a 0.5 -inch subxiphoid incision was made, and a Langenbeck retractor was insinuated on the undersurface of the sternum. Traction was then given via a Rultract ITA retractor (Rultract Inc, Cleveland, Ohio), thereby elevating the lower third of the sternum, which greatly enhanced visualization of the distal end of the RITA. This incision was later used to insert a pleural drain (Figure 2).

- The right pleura was widely opened because this helped in positioning the circumflex vessels for grafting without any hemodynamic compromise. With the use of a bovie at a very low setting, the RITA was harvested in a skeletonized fashion from the subclavian vein proximally to the bifurcation distally. The RITA length was more than adequate to reach the right coronary artery and the right coronary posterior descending artery. The LITA was then harvested in a standard fashion.

- The pericardial fat was removed thoroughly to facilitate exposure. An incision was made on the anterior surface of the pericardium, and the left anterior descending (LAD) artery was exposed. For the lateral and inferior wall vessels, the pericardial incision was extended to the diaphragm and to the phrenic nerve on the left side and as far as possible to the right.

- After heparinization, a LITA RITA Y composite conduit was constructed, and this was used for complete myocardial revascularization by the off-pump CABG technique using only the Guidant Acrobat coronary artery stabilizer (Figure 5). The LITA was anastomosed to the $\mathrm{LAD}$, and the RITA Y was used for sequential grafting of the circumflex and inferior wall vessels (Figures 6 and 7). Patients with low ejection fraction and a dilated LV were grafted on an empty beating heart using the peripheral femoro-femoral cardiopulmonary bypass methodology. Intraoperative assessment of grafts was done using TTFM.

- For cardiac positioning, a wide pericardiotomy was performed anteriorly, and this was opened up in an $\mathrm{H}$ fashion with the left upper and lower limbs of the $\mathrm{H}$ hugging the diaphragmatic surface extending to the right and left pleural spaces, stopping short of the phrenic nerves, thereby enabling the heart to roll into that space while operating on the lateral wall vessels, the right upper and lower limbs of the $\mathrm{H}$ extending to the right side of the heart and the pulmonary artery, respectively. Thereby, the pericardium had 2 leaves: an upper leaf and a lower leaf. 
TABLE 1. Preoperative characteristics

\begin{tabular}{lc}
\hline No. patients & 819 \\
Male/female & $572 / 247$ \\
\hline Age, mean \pm SD (range) & $64.5 \pm 8.5(39-89)$ \\
EF, mean \pm SD & $40 \pm 5.2$ \\
Critical LMS + preoperative & $80(9.8 \%)$ \\
$\quad$ IABP & \\
Poor LV function + preoperative & $36(4.5 \%)$ \\
$\quad$ IABP $(<25 \%)$ & \\
Diabetic & $753(92.0 \%)$ \\
Prior MI & $442(54 \%)$ \\
COPD & $98(12 \%)$ \\
PVD & $81(10 \%)$ \\
Renal & $49(6.0 \%)$ \\
Neurologic & $17(2.1 \%)$ \\
BMI, mean & 27.1 \\
\hline
\end{tabular}

$S D$, Standard deviation; $E F$, ejection fraction; $L M S$, left main stem; $I A B P$, intra-aortic balloon pump; $L V$, left ventricle; $M I$, myocardial infarction; $C O P D$, chronic obstructive pulmonary disease; $P V D$, peripheral vascular disease; $B M I$, body mass index.

\section{Left Anterior Descending Positioning}

Two 2-0 silk sutures were inserted into the edge of the upper leaf of the pericardiotomy and were fixed tautly to the drapes on the right anterior chest wall with artery forceps, thereby bringing the heart to the left and the LAD in front for easy anastomosis.

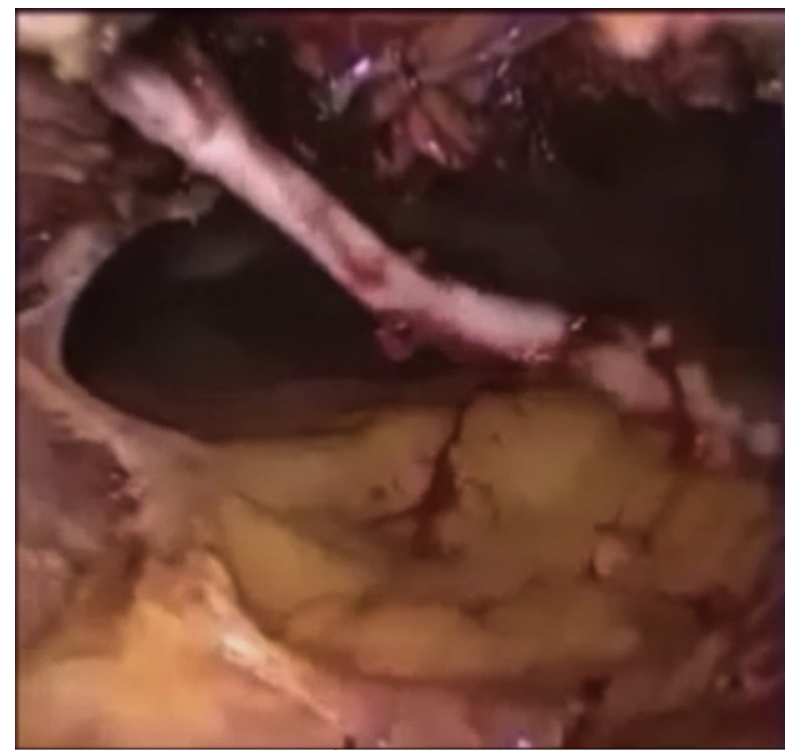

VIDEO 1. 1. LITA RITA surface marking. 2. Left infrathoracic incision. 3. Left minithoracotomy fifth intercostal space. 4. Setup for minimally invasive cardiac surgery CABG. 5. RITA harvesting. 6. Harvested RITA. 7. Harvested LITA-RITA Y. 8. LITA-RITA Y. 9. LITA > LAD. 10. RITA $\mathrm{Y}>$ oblique marginal sequential. 11. RITA $\mathrm{Y}>$ posterior descending artery. 12. RITA $>$ posterior descending artery $>$ oblique marginal; RITA LITA Y; LITA > LAD. Video available at: http://www.jtcvsonline.org/article/ S0022-5223(17)32138-4/fulltext.

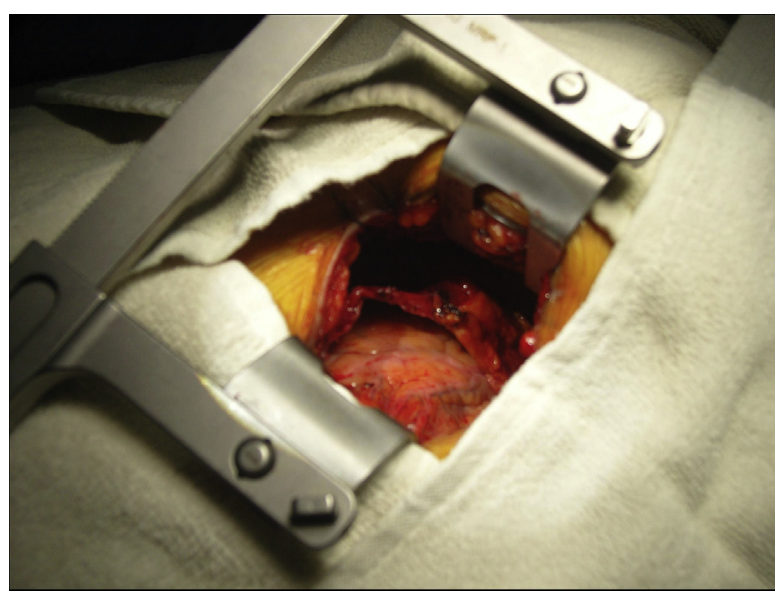

FIGURE 1. Left minithoracotomy.

\section{Positioning for Circumflex Vessels}

The patient was placed in a Trendelenburg position and with the table turned to the right. The sutures inserted into the upper leaf of the pericardiotomy were released, and 2 sutures were inserted into the lower leaf of the pericardiotomy and fixed tautly to the drapes on the left anterior chest wall, thereby enabling easy visualization of the intermediate and circumflex vessels.

\section{Posterior Descending Artery Positioning}

The sutures inserted into the lower leaf of the pericardiotomy were fixed to the drapes on the left anterior chest wall toward the left shoulder with the patient in a Trendelenburg position and with slight rotation of the table to the left.

Most of the patients were extubated on the table and were mobilized within 1 hour of return from the operating room. Analgesia was optimized using the continuous paravertebral block technique with an infusion of $0.25 \%$ sensoricaine. However, because 1 of the patients had a prolonged episode of hypotension after this technique, we stopped and switched to intravenous (IV) fentanyl in the first 24 hours. Oral and IV analgesics such as tramadol or paracetamol were given during the hospital stay, and the patients were sent home with oral paracetamol if needed.

Four important essentials intraoperatively to prevent or minimize postoperative pain are as follows: (1) The incision is made as anterior as possible and never more than 3.5 inches. The intercostal muscles are cut well beyond the incision, and the serratus anterior is always spared. (2) The approach to the thorax is made as far as possible through the fifth intercostal space because the height is greatest of the intercostal spaces. (3) The right pleural drain is always inserted via a subxiphoid incision rather than through the right intercostal space. (4) An intracostal suture technique is used, thereby avoiding compression of the intercostal bundle by the suture material and enabling splinting the intercostal space without compression of the intercostal bundle, thereby reducing postoperative pain.

All monitoring lines and chest drains were removed on the first or second postoperative morning depending on the hemodynamic status. Most of the patients were discharged on postoperative day 3 .

\section{RESULTS}

A total of 819 patients had minimally invasive total arterial myocardial revascularization using BITAs (LITA-RITA Y composite conduit) via a left minithoracotomy. The average number of grafts was 3.1. Intraoperative TTFM was done in 642 patients, totaling 1990 grafts, and 7 grafts 


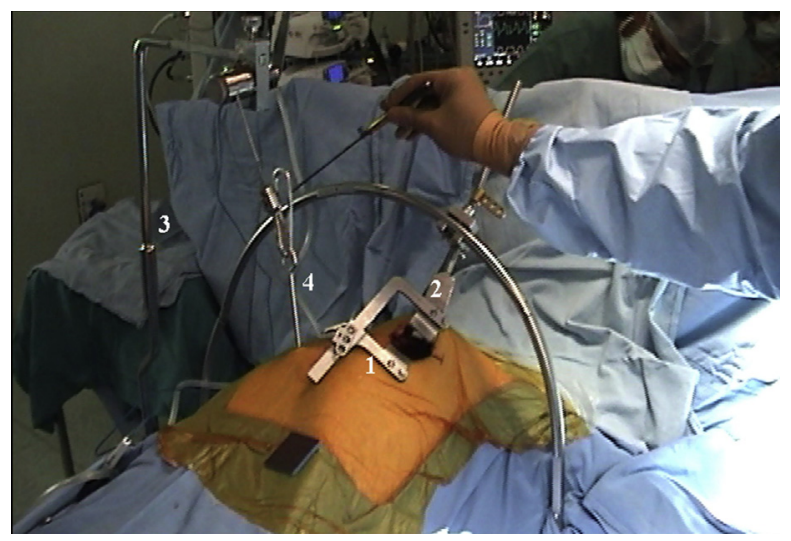

FIGURE 2. Setup for minimally invasive CABG. 1. Minimally invasive cardiac surgery CABG intercostal retractor. 2. Thorac-Pro ITA retractor (Fehling Surgical Instruments Inc, Karlstein, Germany). 3. Rultract retractor. 4. Rultract retractor (Rultract Inc, Cleveland, Ohio) elevating the lower end of the sternum via a subxiphoid incision.

$(0.3 \%)$ had to be revised. A total of 171 patients $(21 \%)$ had 4 grafts, and 558 patients $(68 \%)$ had 3 grafts. Ejection fraction was $40.5 \pm 5.2$. There were 6 mortalities $(0.7 \%)$, and 5 patients $(0.6 \%)$ had reexploration for bleeding. Four patients died of sepsis and multiorgan failure, and 2 patients died of acute renal failure. Four patients $(0.4 \%)$ had an elective conversion to sternotomy because of hemodynamic instability. A total of 80 patients $(9.8 \%)$ had critical left main stem disease, and 36 patients $(4.5 \%)$ with poor LV function $(<25 \%)$ had their grafting carried out using this technique. All patients with significant left main stem had

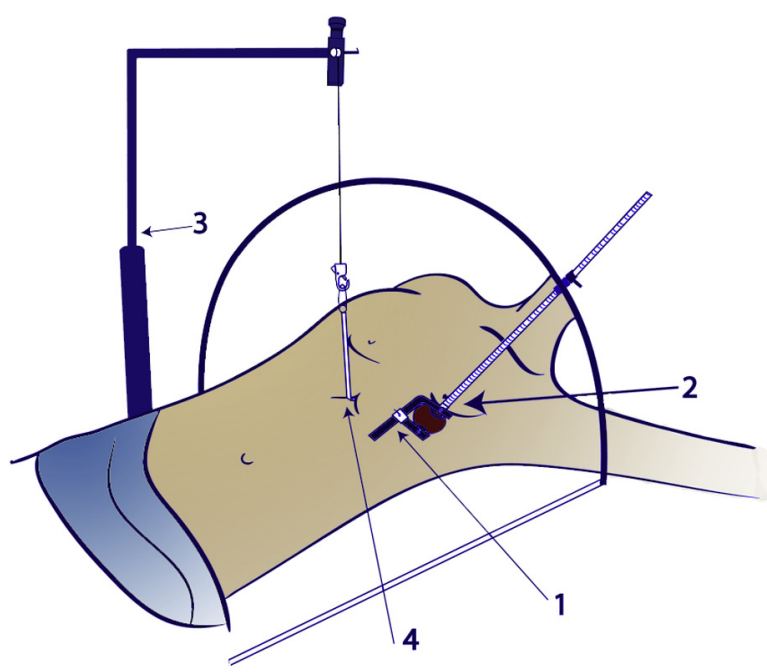

FIGURE 3. Line drawing: positioning of the minimally invasive cardiac surgery instruments and the Rultract retractor (Rultract Inc, Cleveland, Ohio) for harvesting the BITAs. The instruments have been numbered: 1 , minimally invasive cardiac surgery CABG intercostal retractor; 2, Thorac-Pro ITA retractor; 3, Rultract retractor; 4, Rultract retractor elevating the lower end of the sternum via a subxiphoid incision.

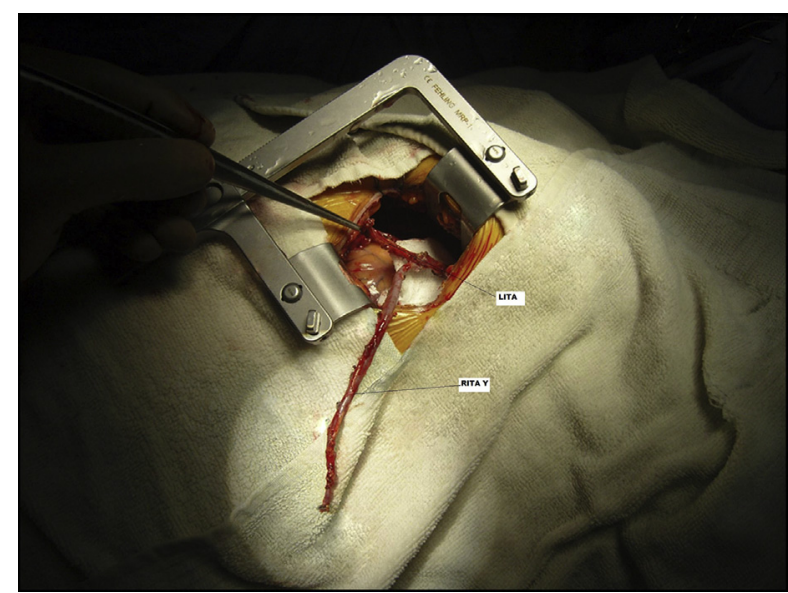

FIGURE 4. LITA RITA Y. LITA, Left internal thoracic artery; RITA Y, right internal thoracic artery $\mathrm{Y}$.

an intra-aortic balloon pump inserted before induction of anesthesia, and patients with poor LV function $(<25 \%)$ and dilated hearts had their grafting done on an empty beating heart with cardiopulmonary bypass established via femoro-femoral peripheral cannulation. The RITA and LITA harvest times were $28.5 \pm 10.2$ minutes and $22.2 \pm 7.6$ minutes, respectively. The total time in the operating room (including extubation) was $295.5 \pm 32.5$ minutes, and operating time was $175.8 \pm 21.6$ minutes. A total of 651 patients $(79 \%)$ were extubated on the table. A total of 8 patients $(0.9 \%)$ required intervention for pleural effusion, and 16 patients $(2 \%)$ had postoperative atrial fibrillation. The strategy for prevention of postoperative atrial fibrillation was as follows: An IV bolus of $150 \mathrm{mg}$ of amiodarone was given before the initial

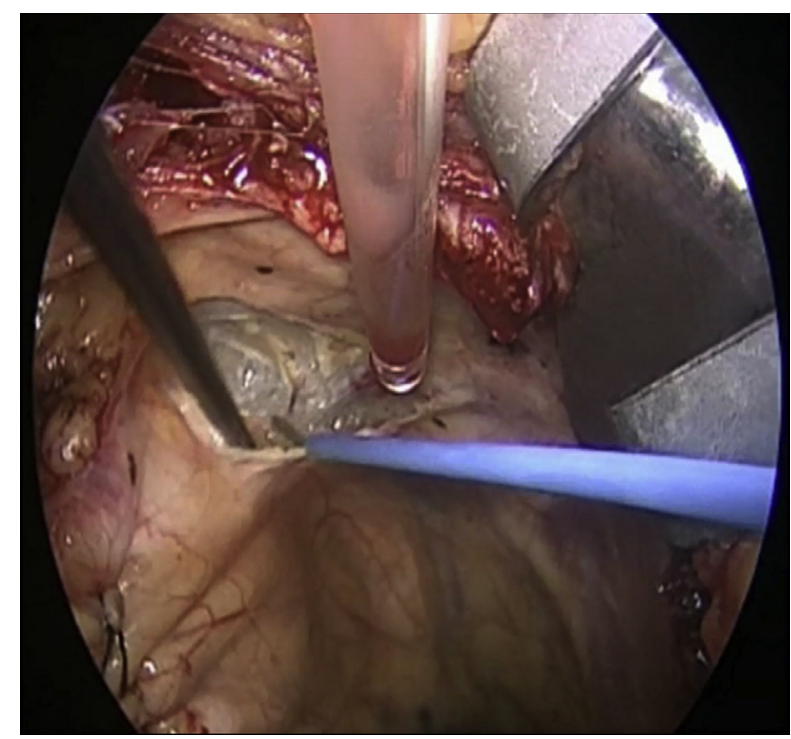

FIGURE 5. Dissection of mediastinal tissue to reach the right hemithorax, surgeon's view. 


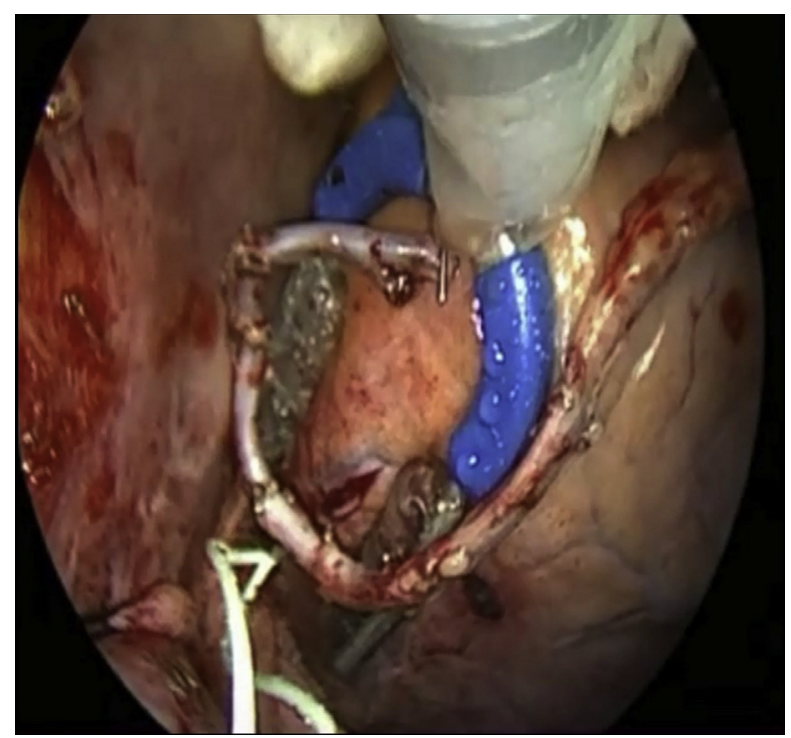

FIGURE 6. Heart positioned for obtuse marginal artery graft.

anastomosis, and then another IV bolus of $150 \mathrm{mg}$ was given after completion of revascularization. This was then followed by infusion of $900 \mathrm{mg}$ of amiodarone for 24 hours. Two grams of IV magnesium sulfate was given intraoperatively; $200 \mathrm{mg}$ of oral amiodarone twice per day was continued for 1 week. The QT intervals were monitored daily. In regard to postoperative recovery, the average patient length of stay was 3.1 days and full recovery was achieved in 2 weeks in majority of the patients. The average length of stay was 3 days for 728 patients ( $89 \%$ ), 4 days for

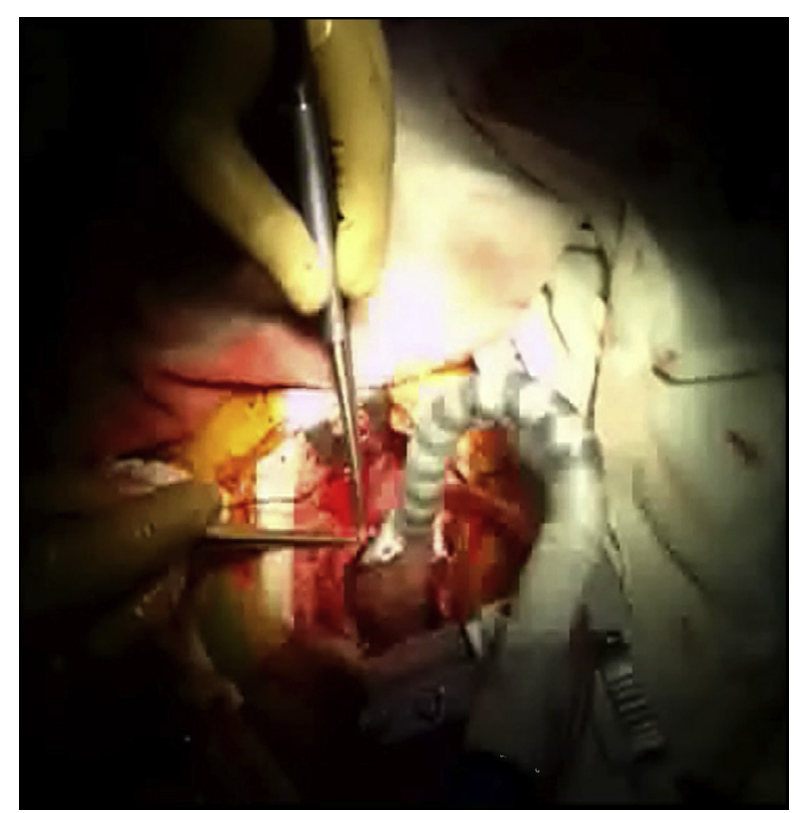

FIGURE 7. Heart positioned and stabilized for posterior descending artery graft.
56 patients $(6.8 \%)$, and 5 days for 35 patients $(4.2 \%)$. Early return to work and full activity were documented in 738 patients $(90 \%)$ in 10 to 14 days and in 81 patients $(10 \%)$ in 15 to 30 days.

Follow-up was complete in 737 patients $(90 \%)$. The mean duration of follow-up was 12.8 months (range, 520.5 ), and $99.3 \%$ of patients were free from major adverse cardiac and cerebrovascular events. Imaging studies were done at 12 months to check for graft patency. As the majority of the patients who underwent surgery were feeling well and had no symptoms, only $195(23 \%)$ consented for an angiogram. A total of 172 patients (21\%) opted for a coronary computed tomography angiogram, and 284 patients $(34 \%)$ consented to a stress test. Four patients $(0.4 \%)$ had recurrence of angina and required reintervention angioplasty. The remainder of the grafts studied by coronary angiogram and computed tomography angiogram were patent, and the stress test showed normal results. There was no late mortality. Distribution of conduits and the target vessels is detailed in Table 2, and operative characteristics and results are shown in Tables 3 and 4.

\section{DISCUSSION}

Calafiore and colleagues ${ }^{5}$ popularized minimally invasive CABG through a small left anterior thoracotomy and reported the largest series, extending the indication to patients with multivessel coronary disease. McGinn and colleagues ${ }^{6}$ have shown that in minimally invasive CABG, applicability, revascularization completeness, morbidity profile, and safety were excellent and were maintained despite rapid procedural adoption. Use of BITAs in CABG has shown improved survival and increased freedom from reintervention. ${ }^{7}$ Total arterial revascularization with composite arterial grafts has clearly improved the midterm and long-term outcomes. ${ }^{8}$ However, the use of BITAs has not been optimal in CABG because of increased incidence of sternal complications, especially in patients with diabetes.

Harvesting of ITAs with conventional thoracoscopic instruments with video assist has been limited because of lack of precision, instrument factors, and limitations. ${ }^{9}$ The introduction of robots has added to the total endoscopic harvest of the ITAs; however, the limitations have been the cost factor, availability, and steep learning curve. ${ }^{10}$

Subramanian and colleagues ${ }^{9}$ reported BITA harvesting with robotic assistance and minimal access multivessel coronary artery bypass. Robotic assistance greatly enhances visualization and thereby results in harvesting longer lengths of conduits, which is essential for multivessel grafting. ${ }^{11,12}$ In our study, for enhanced visualization of the lower thirds of the RITA and the LITA, and in increasing the space required for manipulation of the heart, a 0.5 inch subxiphoid incision was made through which a Langenbeck retractor was insinuated on the undersurface of 
TABLE 2. Distribution of conduits and target vessels

\begin{tabular}{|c|c|c|c|c|c|}
\hline Target coronary & No & $\begin{array}{c}\text { LITA RITA Y } \\
\text { LITA LAD/diagonal }\end{array}$ & $\begin{array}{c}\text { LITA RITA Y } \\
\text { RITA Y sequential }\end{array}$ & $\begin{array}{c}\text { LITA radial Y } \\
\text { Radial Y sequential } \\
\end{array}$ & Saphenous vein \\
\hline LAD & 819 & 818 & - & - & 1 \\
\hline Diagonal & 79 & 79 & - & - & - \\
\hline Ramus & 138 & - & 132 & 6 & - \\
\hline $\mathrm{OM}$ & 576 & - & 570 & 4 & 2 \\
\hline Distal CX & 239 & - & 237 & 2 & - \\
\hline PDA & 651 & - & 643 & 4 & 4 \\
\hline Distal right & 36 & - & 36 & - & - \\
\hline
\end{tabular}

Coronary artery targets are greater than $1.25 \mathrm{~m}$. Total number of grafts, 2538. Mean number of grafts, 3.1. LITA RITA Y, Left internal thoracic artery right internal thoracic artery Y composite conduit; LITA, left internal thoracic artery; $L A D$, left anterior descending artery; RITA, right internal thoracic artery; OM, obtuse marginal artery; CX, circumflex artery; $P D A$, posterior descending artery.

the sternum and traction was given using a Rultract ITA retractor. This elevated the undersurface of the sternum and enabled us to manipulate with ease the minimal access instruments within the thorax and to visualize the distal ends of both the RITA and the LITA. This resulted in our ability to harvest conduits of more than adequate length for complete arterial revascularization. This incision was later used to insert a pleural drain. Further, avoiding a median sternotomy, BITAs were used without increasing the risk for wound dehiscence, particularly noting the large number of patients with diabetes in our study group.

Multivessel coronary artery bypass through minimal access has been performed using peripheral arterial cannulation and cardioplegic arrest. ${ }^{13,14}$ Our technique encompassed a method in which through a 2-inch left minithoracotomy, BITAs of adequate length were conveniently harvested in a skeletonized manner under direct vision. Total arterial off-pump complete myocardial revascularization was then done using the LITA RITA Y composite conduit. This grossly reduced the invasiveness when compared with CABG via a sternotomy.

Vassiliades ${ }^{15}$ has described port-access stabilization in endoscopic coronary artery bypass for LITA to LAD artery anastomoses. In our study, we have used the ACROBAT SUV (Maquet, Rastatt, Germany) coronary artery stabilizer for positioning and stabilization of all coronary targets. The use of intraoperative transesophageal echocardiography while positioning for the various grafts preempted any hemodynamic instability.

The postoperative recovery was good, with a mean hospital stay of 3.1 days and return to full activity within 2 weeks. This compares favorably with other studies. ${ }^{3,9}$ Operating times were comparable or at times better than standard CABG with total operating time: mean \pm standard deviation, $175.8 \pm 21.6$ minutes and total time in the operating room (including extubation), mean \pm standard deviation, $295.5 \pm 32.5$ minutes. In our series, postoperative pain initially was controlled with paravertebral block using continuous sensoricaine infusion for 24 hours, but a persistent hypotensive episode in 1 of the patients after sensoricaine infusion led us to change our practice. Thereafter, analgesia was optimized using a low-dose fentanyl infusion for the first 12 to 24 hours, along with oral analgesics. Rogers and Duffy ${ }^{16}$ concluded that post-thoracotomy pain is fundamentally due to damage to the intercostal nerve, more than the approach technique, and that efforts should be aimed at careful management of the intercostal space. The intracostal suture technique was used, thereby avoiding compression of the intercostal bundle by the suture material and enabling splinting the intercostal space and reducing postoperative pain. Financial benefits for both the patient and the hospital were observed. The midterm and late outcomes have been good. Coronary and computed tomography angiograms at 12 months have shown excellent graft patency, and only 4 patients required reintervention for recurrence of angina.

Diegeler and colleagues ${ }^{17}$ have shown minimally invasive direct CABG to be a safe procedure and have also shown this in patients with multiple-vessel coronary artery disease and in patients with severely reduced LV function. In our study, we have shown the safety of the technique as demonstrated by the low incidence of perioperative and postoperative complications, including morbidity. Potential contraindications to this technique are severe chronic obstructive pulmonary disease, partial pressure of oxygen of less than 60 on room air arterial blood gas moderate to severe renal dysfunction, recent myocardial infarction or cerebrovascular accident, and patients with intermittent atrial fibrillation and moderate mitral regurgitation who required a maze procedure and mitral repair.

We carried out the first 40 cases in the patients with good LV function. As our experience with this technique increased, we started performing coronary artery bypass in patients with left main stem disease and poor LV function $(<25 \%)$ having multivessel disease. In these patients, an 
TABLE 3. Operative characteristics

\begin{tabular}{|c|c|}
\hline No. grafts, mean & 3.1 \\
\hline 4 grafts (LITA RITA Y) & $171(21 \%)$ \\
\hline 3 grafts (LITA RITA Y) & $558(68 \%)$ \\
\hline 2 grafts (LITA RITA Y) & $66(8 \%)$ \\
\hline 1 graft (LITA RITA Y) & $24(3 \%)$ \\
\hline Time for RITA harvest, mean $\pm \mathrm{SD}$, min & $28.5 \pm 10.2$ \\
\hline Time for LITA harvest, mean $\pm \mathrm{SD}$, min & $22.2 \pm 7.6$ \\
\hline Total operating time, mean $\pm \mathrm{SD}$, min & $175.8 \pm 21.6$ \\
\hline $\begin{array}{l}\text { Total time in OR (including extubation), } \\
\text { mean } \pm \mathrm{SD} \text {, min }\end{array}$ & $295.5 \pm 32.5$ \\
\hline Extubation in OR & $651(79.0 \%)$ \\
\hline Conversion to sternotomy & $4(0.4 \%)$ \\
\hline TTFM (patients) & $642(78.3 \%)$ \\
\hline TTFM grafts & $1990(78.3 \%)$ \\
\hline Revision of grafts & $7(0.3 \%)$ \\
\hline
\end{tabular}

intra-aortic balloon pump was introduced before induction of anesthesia to mitigate risk. Few of the patients with low ejection fraction had their grafting done on an empty beating heart with cardiopulmonary bypass established via the peripheral cannulation technique (femoro-femoral bypass). This technique is reproducible; requires the same infrastructure for formal coronary bypass surgery, with the exception being the acquisition of minimally invasive cardiac surgical instrumentation; and can be done on an empty beating heart to aid in training.

The potential advantages of minimally invasive $\mathrm{CABG}$ using BITAs include long-term survival benefit conferred by BITA grafts and elimination of the risk of sternal wound infection, in addition to the established advantages of minimally invasive coronary artery surgery. This approach has the potential for further optimization with hybrid revascularization strategies. ${ }^{18}$

\section{CONCLUSIONS}

This technique will help optimize minimally invasive cardiac surgery and the use of BITAs with its associated benefits, without the invasiveness and related complications of a median sternotomy, especially in patients with diabetes. This technique is also safely reproducible as shown by Kikuchi and colleagues. ${ }^{18}$ This technique can be extended to patients with left main stem disease and poor LV function and can be performed on an empty beating heart using peripheral cannulation for cardiopulmonary bypass. Further, this may allay patient fears of heart surgery and has shown
TABLE 4. Postoperative results

\begin{tabular}{lr}
\hline Mortality & $6(0.7 \%)$ \\
\hline Reexploration for bleeding & $5(0.6 \%)$ \\
\hline Postoperative AF & $16(2.0 \%)$ \\
\hline Pleural effusion & $8(0.9 \%)$ \\
\hline Blood transfusion, mean \pm SD, units & $0.2 \pm 0.05$ \\
Hospital stay & $3.1 \mathrm{~d}($ mean $)$ \\
$3 \mathrm{~d}$ & 728 patients $(89 \%)$ \\
$4 \mathrm{~d}$ & 56 patients $(6.8 \%)$ \\
$5 \mathrm{~d}$ & 35 patients $(4.2 \%)$ \\
Early return to work/full activity & $738(90 \%)$ \\
$10-14 \mathrm{~d}$ & $81(10 \%)$ \\
$15-30 \mathrm{~d}$ & \\
Graft patency data (12 mo) & Graft occlusion, $2 / 195$ \\
Coronary angiogram, $195(23 \%)$ & Graft occlusion, $0 / 172$ \\
CT angiogram, $172(21 \%)$ & $2+$ vessels $/ 184$ \\
Stress test, $284(54 \%)$ & $4(0.4 \%)$ \\
\hline Reintervention (angioplasty) & \\
\hline
\end{tabular}

$A F$, Atrial fibrillation; $S D$, standard deviation; $C T$, computed tomography.

decreased patient mortality and morbidity, shorter hospital stay, early return to active life, good cosmesis and graft patency, and excellent early and midterm outcomes.

\section{Webcast}

You can watch a Webcast of this AATS meeting presentation by going to: https://aats.blob.core.windows.net/ media/17AM/2017-05-01/RM311/05-01-17_Room311_ 1445_NAMBIAR.mp4.

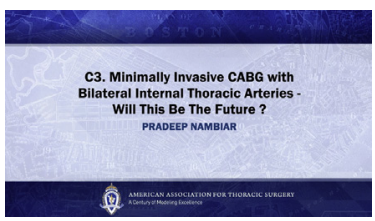

\section{Conflict of Interest Statement}

Authors have nothing to disclose with regard to commercial support.

\section{References}

1. Giambruno V, Hafiz A, Fox SA, Jeanmart H, Cook RC, Khaliel FH, et al. Is the future of coronary arterial revascularization a hybrid approach?: the Canadian Experience across three centers. Innovations (Phila). 2017;12:82-6.

2. Rodriguez ML, Lapierre HR, Sohmer B, Glineur D, Ruel M. Mid-term follow-up of minimally invasive multivessel coronary artery bypass grafting: is the early learning phase detrimental? Innovations (Phila). 2017;12:116-20.

3. Lapierre H, Chan V, Sohmer B, Mesana TG, Ruel M. Minimally invasive coronary artery bypass grafting via a small thoracotomy versus off-pump: a casematched study. Eur J Cardiothorac Surg. 2011;40:804-10. 
4. Nambiar P, Mittal C. Minimally invasive coronary bypass using internal thoracic arteries via a left minithoracotomy - "the Nambiar Technique" Innovations (Phila). 2013;420-6.

5. Calafiore AM, Di Giammarco G, Teodori G, Bosco G, D'Annunzio E, Barsotti A, et al. Left anterior descending coronary artery grafting via left anterior small thoracotomy without cardiopulmonary bypass. Ann Thorac Surg. 1996;61:1658-63.

6. McGinn JT Jr, Usman S, Lapierre H, Pothula VR, Mesana TG, Ruel M. Minimally invasive coronary artery bypass grafting: dual-center experience in 450 consecutive patients. Circulation. 2009;120(suppl):S78-84.

7. Lytle BW, Blackstone EH, Loop FD. Two internal thoracic artery grafts are better than one. J Thorac Cardiovasc Surg. 1999;117:855-72.

8. Muneretto C, Negri A, Manfredi J. Safety and usefulness of composite grafts for total arterial myocardial revascularization: a prospective randomized evaluation. J Thorac Cardiovasc Surg. 2003;125:826-35.

9. Subramanian VA, Patel NU, Patel NC, Loulmet DF. Robotic assisted multivessel minimally invasive direct coronary artery bypass with port-access stabilization and cardiac positioning: paving the way for outpatient coronary. surgery? Ann Thorac Surg. 2005;79:1590-6.

10. Jones B, Desai P, Poston R. Establishing the case for minimally invasive, roboticassisted $\mathrm{CABG}$ in the treatment of multivessel coronary artery disease. Heart Surg Forum. 2009;12:E147-9.

11. Cichon R, Kappert U, Schneider J, Byhahn C, Mierdl S, Westphal K, et al. Robotic-enhanced arterial revascularization for multivessel coronary artery disease. Ann Thorac Surg. 2000;70:1060-2.
12. Dogan S, Aybek T, Andressen E, Byhahn C, Mierdl S, Westphal K, et al. Totally endoscopic coronary artery bypass grafting on cardiopulmonary bypass with robotically enhanced telemanipulation: report of forty-five cases. J Thorac Cardiovasc Surg. 2002;123:1125-31.

13. Gulielmos V, Knaut M, Cichon R, Brandt M, Jost T, Matschke K, et al. Minimally invasive surgical treatment of coronary artery multivessel disease. Ann Thorac Surg. 1998;66:1018-21

14. Gulielmos V, Brandt M, Knaut M, Cichon R, Wagner FM, Kappert U, et al. The Dresden approach for complete multivessel revascularization. Ann Thorac Surg. 1999;68:1502-5.

15. Vassiliades TA Jr. Endoscopic-assisted atraumatic coronary artery bypass. Asian Cardiovasc Thorac Ann. 2003;11:359-61.

16. Rogers ML, Duffy JP. Surgical aspects of chronic post-thoracotomy pain. Eur J Cardiothorac Surg. 2000;18:711-6.

17. Diegeler A, Matin M, Falk V, Binner C, Walther T, Autschbach R, et al. Quality assessment in minimally invasive coronary artery bypass grafting. Eur J Cardiothorac Surg. 1999;16(suppl 2):S67-72.

18. Kikuchi K, Chen X, Mori M, Kurata A, Tao L. Perioperative outcomes of offpump minimally invasive coronary artery bypass grafting with bilateral internal thoracic arteries under direct vision. Interact Cardiovasc Thorac Surg. 2017;24: 696-701.

Key Words: coronary artery bypass grafting, internal thoracic arteries, left minithoracotomy, minimally invasive

Readers who found these articles interesting may also like to read the following papers found in recent and future issues of our sister publications, Seminars in Thoracic and Cardiovascular Surgery and Operative Techniques in Thoracic and Cardiovascular Surgery!

\section{Acquired: Coronary}

NEW AND VIEWS: Training in Coronary Artery Bypass Surgery: Tips and Tricks of the Trade Giuseppe Maria Raffa. Semin Thoracic Surg 2017:137-142.

ORIGINAL SUBMISSION: Remote Ischemic Preconditioning in High Risk Cardiovascular Surgery Patients: a RandomizedControlled Trial Nicole S. Coverdale. Semin Thoracic Surg 2017: In press.

ORIGINAL SUBMISSION: World Wide Trends in Multi-Arterial CABG Surgery 2004-2014: A Tale of Two Continents Thomas A. Schwann. Semin Thoracic Surg 2017: In press.

Editorial Commentary: Multi-arterial Coronary Artery Bypass Grafting Surgery: Best of Times, Worst of Times? Edward Y. Sako. Semin Thoracic Surg 2017: In press.

ORIGINAL SUBMISSION: How Safe Is it to Train Residents to Perform Coronary Surgery With Multiple Arterial Grafting? Nineteen Years of Training at a Single Institution Umberto Benedetto. Semin Thoracic Surg 2017:12-22.

Editorial Commentary: Hey! Teacher! Leave Them Kids Alone! Joshua L. Hermsen. Semin Thoracic Surg 2017:23-24.

ORIGINAL SUBMISSION: Surgical Unroofing for Anomalous Aortic Origin of Coronary Arteries Sarah A. Schubert. Oper Tech Thorac Cardiovasc 2016:162-177.

ORIGINAL SUBMISSION: Surgical Treatment of Anomalous Aortic Origin of Coronary Arteries the Reimplantation Technique and Its Modifications Thierry Carrel. Oper Tech Thorac Cardiovasc 2016:178-201. 